\title{
Definition of Learner Choices from Learner-Driven Learning for Ubiquitous e-Learning Systems and its Application in the AdaptWeb Platform
}

\author{
Alessandro da Silveira Dias, Leandro Krug Wives \\ Instituto de Informática - Universidade Federal do Rio Grande do Sul (UFRGS) \\ Porto Alegre, RS - Brazil \\ \{alessandro.dias, leandro.wives\} @inf.ufrgs.br
}

\begin{abstract}
We noticed that learner users usually perform a set of choices or make decisions during learning, depending on the e-learning platform. This set of choices belongs to the Learner-driven Learning paradigm from Education. In this paper, we state these choices for e-learning systems, based on user-interaction partners and navigation patterns we noticed while performing a systematic review on e-learning systems. Moreover, we present how these choices are implemented in the AdaptWeb platform, a ubiquitous e-learning system for formal education.
\end{abstract}

Resumo. Nós percebemos que os usuários de perfil estudante geralmente realizam um conjunto de escolhas ou tomadas de decisão durante a aprendizagem, dependendo da plataforma de e-learning utilizada. Esse conjunto de escolhas pertence ao paradigma de Aprendizagem Autodirigida da Educação. Neste artigo, definimos essas escolhas em sistemas de e-learning, com base em padrões de interação e de navegação de usuários que observamos em diferentes sistemas e-learning durante uma revisão sistemática que realizamos. Além disso, apresentamos como essas escolhas são implementadas no AdaptWeb, um sistema de e-learning formal e ubíquo.

\section{Introduction}

During a systematic review on recommender systems of learning objects (LOs) we noticed that learner-users usually perform a set of choices or make decisions during learning (e.g., "what to learn", "how to learn", "with whom to learn", "in which pathway to learn", "where to learn", among others), depending on the platform used to learn. This set of choices belongs to the Learner-driven Learning paradigm from Education [Alexander et al., 2004; Watkins et al., 2007].

The Learner-driven Learning paradigm focuses on the process by which the learner takes control of his own learning, in particular, how he sets his own learning goals, how he finds the appropriate resources, how he decides what learning methods he uses, and how he evaluates his progress [Alexander et al., 2004]. It is interrelated with other terms of Education and Psychology, such as autonomous learning, active learning, responsible learning and self-regulated learning. 
VII Congresso Brasileiro de Informática na Educação (CBIE 2018)

Anais do XXIX Simpósio Brasileiro de Informática na Educação (SBIE 2018)

In this research, we review the origin of the Learner-driven Learning paradigm: the Student-centered Learning paradigm, and we analyze this learning paradigm from the point of view of formal and non-formal learning environments. In both cases, the learner performs choices during the learning process.

The set of choices from the learner-driven learning are presented in a more general way in Alexander et al. (2004), Miliband (2006), Watkins et al. (2007), LEADLAB (2010), Ginsberg (2015), and others. Then we specify these choices for e-learning systems, based on user-interaction patterns and navigational patterns that we have noticed while we knew different e-learning systems during the systematic review performed. To the best of our knowledge, we are the first to specify these choices for e-learning systems.

We also analyze how different categories of e-learning systems, such as Massive Open Online Courses, Online Discovery Learning Spaces and Personal Learning Environments, enable users to perform such choices.

Finally, we present the learner-user choices from the learner-driven learning in the last version of the AdaptWeb platform ${ }^{1}$, a ubiquitous e-learning system for formal education. Users can use AdaptWeb where and when they want, by computers, notebooks, tablets, smartphones, and connected TVs. This system allows the user to make almost all types of choices during learning based on the learner-driven learning. Moreover, AdaptWeb uses the result of the user choices (i.e., the fusion of explicit interactions, learning trace, and contextual information) as a source of information for an LO recommender system.

The rest of this paper is organized as follows: Section 2 gives a brief overview of related works. Section 3 presents the Learner-driven Learning paradigm and related concepts. Section 4 presents the mapping of learner choices from learner-driven learning to e-learning systems. Section 5 presents such learner-user choices in the AdaptWeb and briefly presents how to use such choices for the personalization of learning, by a recommender system of LOs. And Section 6 presents our conclusions.

\section{Related Work}

Many works, such as iNACOL (2013) and Gates-Dell-EDUCAUSE (2017), use the choices from the learner-driven paradigm to define the term "personalized learning". For instance, Gates-Dell-EDUCAUSE (2017) present a working definition of personalized learning that is intended as a model to help educators design student-centered instructional models in schools. In this model, (1) each student has a learning profile, (2) each student follows a customized learning pathway, (3) the progress of students is competency-based, and (4) learning occurs in flexible/blended learning environments.

Drachsler et al. (2015) present a review of recommender systems in Technology Enhanced Learning. Recommender systems are filtering systems that usually reduce a considerable number of options in a user choice to a smaller subset and then leave it to the user to select an option from the subset. This work presents different recommendation tasks, such as finding good LOs, finding peer learners and

\footnotetext{
${ }^{1}$ http://adaptweb.sourceforge.net/
} 
VII Congresso Brasileiro de Informática na Educação (CBIE 2018)

Anais do XXIX Simpósio Brasileiro de Informática na Educação (SBIE 2018)

recommending learning pathways. These three recommendation tasks are related to these learner choices: "what to learn", "with whom to learn", and "in which learning pathway to learn". Therefore, when learner-users have many options in a choice, a recommender system can help them deal with the overload of options.

Zheng et al. (2014) formalized the recommendation task of "context suggestion". Recommenders systems of context are applied, for instance, to maximize user experience, which refers to a person's emotions and attitudes about using a particular product, system or service. For instance, a recommender system that performs this recommendation task can identify the best contexts (place, time and/or companion) for a learner-user to learn some content. In this best context, for instance, learning might be enhanced. Recommendation of places, times and companions are related to the following learner choices: "where to learn", "when to learn" and "with whom to learn".

Zhuhadar and Butterfield (2014) launch the idea of an LO recommendation approach for MOOCs based in the continued monitored user interactions into all stages of course, in the learning performance and the previous knowledge of the user. We see that this approach includes all choices of the learner-driven learning.

\section{Learner-Driven Learning}

Learner-driven learning is a learning paradigm that focuses on the process by which the learner takes control of his own learning, in particular, how he sets his own learning goals, how he finds the appropriate resources, how he decides what learning methods he uses, and how he evaluates his progress [Alexander et al., 2004]. It is interrelated with other terms of Education and Psychology, such as autonomous learning, active learning, responsible learning and self-regulated learning.

Next, we present the origin of the Learner-driven Learning paradigm and analyze it from the point of view of formal and non-formal learning environments.

\subsection{Origin of the Learner-Driven Learning Paradigm}

There are different paradigms (or approaches/models) of learning. One of them is the Teacher-centered Learning, which is based on the transmission of knowledge from the teacher to a mass of students. Another paradigm is the Student-centered Learning, which is based on learning activities that aim to provide the development of the student in multiple aspects (intellectual, cognitive, social and emotional).

The Student-centered Learning approach, in a specific way, refers to forms of instruction that, for example, give students opportunities to lead learning activities, participate more actively in discussions, design their own learning projects, explore topics that interest them, and generally contribute to the design of their own course of study. Learning also occurs outside the classroom learning space, for example, in online classes on the Web and exchange experiences. In this case, the teacher acts as a facilitator of learning, for instance, by helping learners to filter content from learning and to create their own learning path.

It is in this context of student-centered learning that the idea of learner-driven learning arises, in which students can make choices in and during their learning. 
VII Congresso Brasileiro de Informática na Educação (CBIE 2018)

Anais do XXIX Simpósio Brasileiro de Informática na Educação (SBIE 2018)

\subsection{Learner-Driven Learning Paradigm from Different Points of View}

Learner-driven learning can be analyzed from different points of view. In this paper, we analyze it according to the learning environment: whether the learning environment is formal or non-formal.

Formal learning environments are those where learning occurs in the presence of a teacher (a facilitator) within an educational institution, and at the end, the student receives a training certificate. Non-formal learning environments are those where the person is not being led by a facilitator of any educational institution, and this person intends to learn. There are also informal learning environments, which are any environment of everyday life where learning occurs, not necessarily intentional [Overwien, 2017].

\subsubsection{Learner-Driven Learning in Formal Learning Environments}

Watkins et al. (2007) point out that, in the present time, learning should focus less on the acquisition of knowledge by people and more on building knowledge with other people. The Teacher-centered Learning model, which relies on the transmission of teacher knowledge to a mass of students, worked well to the point where the body of the information was finite. But today the situation is different, for example, much information is available - learners, both adults, and children need to know how to find and select relevant information, how to process them, how to connect them, and how to use them; and learning occurs anywhere and at any time.

In this new context, it is necessary to have an "effective learning" and "an effective learner" [Watkins et al., 2007]. Effective learning is (1) an activity of construction (2) handled with (or in the context of) others (3), driven by the learner (4), the monitoring and review of the effectiveness of approaches and strategies for the goals and context. An effective learner (1) is active and strategic (2), is skilled in collaboration (3), takes responsibility for their learning (4), understands their learning and plans, monitors and reflects on their learning. These are the four dimensions of effective learning, and what an effective learner under these four dimensions means.

Once the concept of effective learning is understood, one can understand the meaning of learner-driven learning in the context of formal learning. In these environments, according to Watkins et al. (2007), learner-driven learning is one of the dimensions of effective learning, focusing on learner choices and decisions, learning planning, and review (reflection) before, during, and after learning.

This means, in a practical way, that learner-driven learning can be seen as a process. Before to start, students set their learning objectives (take the "what to learn" decision), considering their personal interests and aspirations. During this assembly, students sometimes realize their limitations and then set learning goals together with the teacher (the facilitator). The teacher should make students aware of their needs to learn, i..e., "why" they need to learn those subjects. Teachers, from their global knowledge, may suggest necessary prerequisite subjects to learn what the learners aim to learn or can encourage learners to review their learning objectives set. During learning, students take decisions related to "how to learn" the subjects, the "order in which they learn the subjects", "where to learn", "when to learn", "with whom to learn", among others. The teacher acts at all times facilitating learning, for example, motivating students, helping 
VII Congresso Brasileiro de Informática na Educação (CBIE 2018)

Anais do XXIX Simpósio Brasileiro de Informática na Educação (SBIE 2018)

them to see the subject being learned, and listening to them (making comments about their learning, for example, how they can learn more and better). At the end, students demonstrate what they have learned through some product and self-evaluate their learning.

\subsubsection{Learner-Driven Learning in Non-formal Learning Environments}

In these settings, learner-driven learning is related to lifelong learning. It is defined as "all lifelong learning activity, with the aim of improving knowledge, skills, and competencies from a personal, civic, social and/or professional perspective" [CEC, 2001]. It encompasses learning combinations in formal, non-formal and informal learning environments; it is a continuous, voluntary and self-motivated learning. The apprentice learns with the purpose of meeting their personal and professional needs.

Moreover, in a non-formal learning environment, lifelong learning can be seen in a variety of contexts, such as learning in the workplace, in exchanges, in social learning networks, and in personal learning environments (these are described in Section 4.2).

In non-formal learning environments, learning is a naturally learner-driven way. In these environments, learners can perform the same process of self-directed learning used in formal learning environments with effective learning: before to start, setting their learning objectives, becoming aware of what they must learn and defining the learning strategy to use; then, by executing their learning and self-monitoring their progress; and at the end, evaluating their learning. In all these activities, learners perform choices, make decisions and critically reflects on what they have done.

As can be seen, regardless of whether it is a formal or non-formal learning environment, or without the use of computer technologies, during learner-driven learning the learner performs a series of choices.

\section{Learner-Driven Learning in E-learning Systems}

Now we define the learner choices from learner-driven learning for e-learning Systems. To the best of our knowledge, we are the first to specify these choices for e-learning systems. Then, we analyze how different categories of e-learning systems, such as Massive Open Online Courses (MOOC), enable the user to perform such choices.

\subsection{Defining the Learner Choices for E-learning Systems}

The set of choices from the Learner-driven Learning paradigm are presented in a more general way in Alexander et al. (2004), Miliband (2006), Watkins et al. (2007), LEADLAB (2010), Ginsberg (2015), and others. Then we specify these choices for elearning systems as follows, based on user-interaction patterns and navigational patterns we noticed while we knew different e-learning systems during a systematic review.

A choice of type what to learn means the topic of knowledge a user preferred or wanted to learn. For instance, when the user is learning UML, this user has different diagrams to learn, e.g., Sequence diagram, Class diagram, Timing Diagrams, Activities diagram, etc. Ahead of these options, let's suppose the user chooses the Timing Diagrams to learn. 
VII Congresso Brasileiro de Informática na Educação (CBIE 2018)

Anais do XXIX Simpósio Brasileiro de Informática na Educação (SBIE 2018)

The sequence of topics over time the user preferred to follow to learn results in an upper-level type of choice in which learning pathway to learn from. For instance, when the user is learning UML and prefers to start learning the Timing Diagrams, then this user may choose the Sequence Diagram, then the Activities Diagram, and so on.

A choice of type how to learn specifies what LOs a user preferred to use to learn a topic. For example, a subject can be learned using hypertext, a simulator, a video following a deductive learning strategy or an inductive learning strategy; let's say that ahead these options, the user chooses the simulator to learn.

Choices of the kind where to learn and when to learn mean, respectively, the geographic place and the time the user preferred to use to learn. For instance, the user chose to learn on Tuesday at home, and Friday at the lab.

Choices of the type with whom to learn mean the people the user interacted to learn a topic. For instance, in MOOCs, as it is common to have thousands of students, there is no way to have a team of tutors available. Thus when students do not understand a content using the available LOs, they seek another user in the system to learn from.

Choices of type how much to learn mean the amount of knowledge the user learned of a topic. It can be measured in closed-corpus applications [Manouselis et al. 2010], in this case, e-learning systems designed for formal education, i.e., those where the learning environment, learning resources, learning pathways and assessment procedures are structured and receive maintenance. Thus, it is easy to measure the amount of knowledge the user learned of a topic.

In the case of social learning networks, these are open-corpus applications [Manouselis et al. 2010], i.e., applications with the absence of structure and maintenance. In these, as the knowledge increases continuously by the user community, there is no way to measure knowledge for a topic.

Choices of type how to assess learning mean how users measured their knowledge of a topic. For instance, in an e-learning system, there are different ways to assess the user's learning: quick online test, bibliographical research, audio-visual presentation, teamwork implementation project, through dialectics, presenting eportfolios, and so on. For instance, ahead of these options, the user preferred to be assessed by an audio-visual presentation.

\subsection{The Learner Choices in Categories of E-learning Systems}

There are different categories (or models) of e-learning systems, such as Computer Based Training, Web-Based Training, Computer Supported Cooperative Learning, etc. Some of them are presented below.

Online Discovery Learning Spaces: correspond to learning environments that allow an active learning experience and self-directed by the learner. In systems of this model, learner-users construct their knowledge through the exploration of LOs, that is, they make choices about "what to learn", "in which pathway to learn" and "how to learn". If they are available on the Internet, users can choose "when to learn" and "where to learn". Some systems provide LOs for self-evaluation ("how to assess learning"). If the system is a social learning network, users can seek other users for peer learning ("with whom to learn"). 
VII Congresso Brasileiro de Informática na Educação (CBIE 2018)

Anais do XXIX Simpósio Brasileiro de Informática na Educação (SBIE 2018)

Personal Learning Environments: learning is a lifelong learning process, that is, it is continuous, voluntary, self-motivated and self-directed to meet personal and professional needs. To support this, systems where the learner can create their own learning goals and control the management of their own lifelong learning emerged. Such systems often involve Web 2.0 services, such as social networking and online discovery learning spaces. In systems of this model, generally, all kinds of choices are observed: "what to learn", "with whom to learn", etc.

Massive Open Online Courses: correspond to open, free and accessible online courses for a large simultaneous audience. These courses are generally for higher education and provided by renowned universities. In this model, the learner usually makes choices about "when to learn", "where to learn", and "with whom to learn", since it is not possible to have teachers and tutors to help thousands of students. As mentioned before, this last choice is made when the learner cannot learn alone only using the available LOs.

As it can be seen, the different categories of e-learning systems naturally involve choices from the learner-driven learning by the learner-user. These technologies encourage the user to direct their own learning; the user becomes responsible for creating their own knowledge.

\section{Learner User Choices from Learner-Driven Learning in the AdaptWeb Platform}

In this section, we present the learner-user choices from learner-driven learning in the last version of the AdaptWeb platform. We use an online course of Interaction Diagrams of UML in the AdaptWeb to illustrate how the learner-user performs such choices. This system allows the user to perform almost all types of choices from the learner-driven learning during learning.

\subsection{Learning Process in the AdaptWeb Platform}

In the latest version of the AdaptWeb, the creation and structuring of online courses occur as follows. The teacher performs such tasks through an authorship tool of the system. Firstly, the teacher creates an online course and defines the set of topics. Then, for each topic, the teacher informs metadata (title, description, category, etc.), determines prerequisites, associates a set of LOs from a repository to each topic, and creates an online test. The LOs have metadata that follow the IEEE LOM standard. After creating and structuring the course, the teacher publishes the course.

In general, the learning process in AdaptWeb occurs as follows: it has a beginning point; a learning cycle, where the leaner user learns one topic of the course by cycle; and a finish point. This process is detailed below.

When the user (the student) begins the course, the system presents an introductory text, and the user can choose complementary topics to learn, optionally with teacher's help, according to her personal preferences and needs. This is a "what to learn" choice. With this, the user builds a customized program course, composed of the mandatory topics and the chosen complementary topics. 
VII Congresso Brasileiro de Informática na Educação (CBIE 2018)

Anais do XXIX Simpósio Brasileiro de Informática na Educação (SBIE 2018)

After performing this choice, the learning cycle starts. During the progress of the course, the system asks the user "which of the following topics do you want to learn from now on?" and provides the topics available for them to learn, according to the topics they have already completed, and to the prerequisites not yet learned. For each available topic, a brief overview is presented. The sequence of choices gives rise to the users' learning pathway into the course. The sequence of topics the user preferred to follow to learn over time results in the upper-level type of choice "in which learning pathway to learn". It is a type of user trace into the system, a learning trace.

Within each topic of the course, the user can learn its content in different ways, that is, using different LOs according to their learning preferences and context restrictions. Each topic to be learned is associated with several LOs, from the LO repository. Figure 1 presents the screen of topics, where the user performs "how to learn" choices.

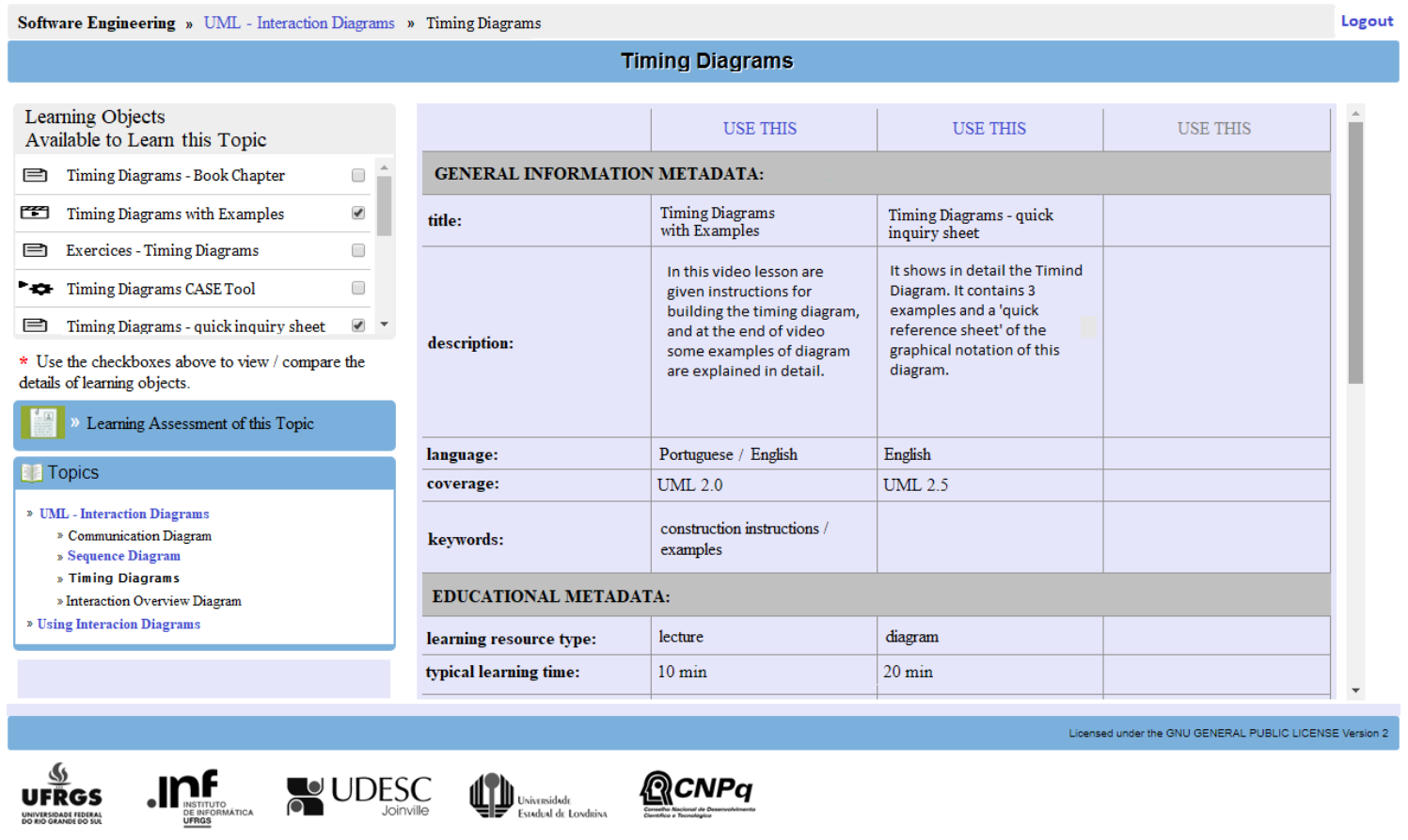

\section{Figure 1. The screen of AdaptWeb where the user performs "how to learn" choices}

Figure 1 presents the moment in which the user is learning the topic Timing Diagrams of UML. This topic has 12 LOs to learn from; they are presented in the list on the left side. When the user selects an LO, the system displays the most relevant metadata [Dias and Wives 2018]. The user uses this information to compare and choose LOs to use to learn. Using the link "Use this", she accesses the LO to learn, or to quickly check the LO inside, before taking the final decision for what LO to use.

In relation to "with whom to learn", AdaptWeb has modules for performing collaboration and communication. There is a forum where the user can create a topic about a subject, and then, all the users can discuss the matter. Moreover, users can exchange private text messages to each other, for instance, one user sends a message seeking to learn content from another user (a "with whom to learn" choice). In relation 
VII Congresso Brasileiro de Informática na Educação (CBIE 2018)

Anais do XXIX Simpósio Brasileiro de Informática na Educação (SBIE 2018)

to "where to learn" and "when to learn", these choices correspond to the place and time the user uses the system. These are recorded by the system as contextual information.

In relation to "how much to learn" (from a topic) choice, AdaptWeb allows the user to perform these choices, for instance, when users already know some part of the content of the topic they can skip that part. However, the last version of AdaptWeb doesn't register this kind of choice. The LOs used in AdaptWeb come from different providers; many are "black-boxes", therefore we are not able to register these choices. If LOs could inform clients (e-learning systems) the parts inside them that users used to learn, we would be able to register this choice. In relation to "how to assess learning", there are only multiple-choice online tests in AdaptWeb. Therefore there are no "how to assess learning" options to choose from.

AdaptWeb uses the result of all user-leaner choices (i.e., the fusion of explicit interactions, learning trace, and contextual information) as a source of information for performing recommendations, and for dynamic leaner profiling. The list of LOs presented in Figure 1 is a personalized list of LOs to the user. Therefore, one usage of the learner choice is for learning personalization.

Once the user finishes learning one topic, she takes the online test, by the link under the list of LOs (Figure 1). Optionally, the user can return to the topics made previously by the "tree of topics" (Figure 1) of the customized program course. When all the topics have been learned, the course ends.

\section{Conclusions}

In this paper we reviewed the Learner-driven Learning paradigm and its choices: "what to learn", "how to learn", "whom to learn", "in which learning pathway to learn", "where to learn", "when to learn", "how much to learn", and "how to assess learning". We knew that in different categories of e-learning systems, such as Massive Open Online Courses, Personal Learning Environments, and Online Discovery Learning Spaces, the learner-user performs three or more choices, and the availability of choices depends on the e-learning system.

We specify these choices for e-learning systems, based on user-interaction patterns and navigational patterns we noticed while we knew different e-learning systems during the systematic review we performed. To the best of our knowledge, we are the first to specify these choices for e-learning systems.

For illustration, we presented the learner-user choices in the AdaptWeb platform, a ubiquitous e-learning system for formal education, and discussed the learner-user choices on non-formal learning, for instance, in social learning networks. In the AdaptWeb we briefly presented how to use such choices for learning personalization, by a recommender system of LOs.

Through this example, we can see that learners from formal education (in schools and universities, and in-company training) can benefit in systems that use these choices to enhance learning. As such learner choices can be performed both informal and non-formal learning environments, learners in non-formal education using technology enhanced learning that uses these choices can benefit too. 
VII Congresso Brasileiro de Informática na Educação (CBIE 2018)

Anais do XXIX Simpósio Brasileiro de Informática na Educação (SBIE 2018)

\section{Acknowledgments}

This work is partially supported by $\mathrm{CNPq}$ (Brazilian Council for Scientific and Technological Development), FAPERGS, and CAPES.

\section{References}

Alexander, S. Kernohan, G. and Mccullagh, P. (2004) Self-directed and lifelong learning. In: Global Health Informatics Education v.109. p.152-66.

CEC - Commission of the European Communities (2001) Communication from the commission - Making a European Area of Lifelong Learning a Reality. Report.

Dias, A. S. Wives, L. K. (2018) Assessment of the Most Relevant Learning Object Metadata: Relieving the Learner-User from Information Overload. In: Proceedings of the 10th International Conference on Computer Supported Education (CSEDU).

Drachsler, H. Verbert, K. Santos, O. and Manouselis, N. (2015) Panorama of Recommender Systems to Support Learning. In: Ricci F., Rokach L., Shapira B. (eds) Recommender Systems Handbook. Springer, Boston, MA, p.421-451.

Gates-Dell-EDUCAUSE - Bill \& Melinda Gates Foundation, the Michael and Susan Dell Foundation, and EDUCAUSE (2017) A working definition of personalized learning. Available in: <https://www.documentcloud.org/documents/1311874personalized-learning-working-definition-fall2014.html>. Access in: 20 jul. 2017.

Ginsberg, M. B. (2015) Excited to Learn: Motivation and Culturally Responsive Teaching. Corwin Press.

iNACOL - International Association for K-12 Online Learning; Patrick, S. Kennedy, K. Powell, A (2013) Mean What You Say: Defining and Integrating Personalized, Blended and Competency Education.

LEADLAB - The LEADLAB Project (2010) Available in: <http://leadlab.euproject.org/ services/files/Download/LEADLABMODEL-EN.pdf>. Access in: 25 feb. 2017.

Manouselis, N. Vuorikari, R., and Assche, F. V. (2010) Collaborative recommendation of e-learning resources: an experimental investigation. In: Journal of Computer Assisted Learning 26(4):227-242. https://doi.org/10.1111/j.1365-2729.2010.00362.x.

Miliband, D. (2006) Choice and voice in personalized learning. In: OECD, Personalizing education. http://dx.doi.org/10.1787/9789264036604-2-en.

Overwien, B. (2017) The history of the term Informal Learning. Available in: <https://www.giz.de/expertise/html/12692.html>. Access in: 01 jun. 2018.

Watkins C, Carnell E, Lodge C (2007) Effective Learning in Classrooms. London, Paul Chapman Publishing. DOI= http://dx.doi.org/10.4135/9781446211472.

Zheng, Y. Mobasher, B. and Burke, R. (2014) Context Recommendation Using Multilabel Classification. In: Proceedings of the 2014 IEEE/WIC/ACM International Joint Conferences on Web Intelligence (WI) and Intelligent Agent Technologies (IAT).

Zhuhadar, L. and Butterfield, J. (2014) Analyzing Students Logs in Open Online Courses Using SNA Techniques, In: Proceedings of the 20th Americas Conference on Information Systems, AMCIS 2014, Savannah, Georgia, USA. 